NBER WORKING PAPER SERIES

\begin{abstract}
UNRAVELING THE PRODUCTIVITY GROWTH SLOWDOWN IN THE U.S., CANADA AND JAPAN: THE EFFECTS OF
\end{abstract} SUBEQUILIBRIUM, SCALE ECONOMIES AND MARKUPS

\author{
Catherine J. Morrison
}

Working Paper No. 2993

\author{
NATIONAL BUREAU OF ECONOMIC RESEARCH \\ 1050 Massachusetts Avenue \\ Cambridge, MA 02138 \\ June 1989
}

Research support from the National Science Foundation, Grant \#SES87-08211, is gratefully acknowledged. This paper is part of NBER's research program in
Productivity. Any opinions expressed the National Bureau of Economic Research. 
NBER Working Paper \#2993

June 1989

\title{
UNRAVELING THE PRODUCTIVITY GROWTH SLOWDOWN IN THE U.S., CANADA AND JAPAN: THE EFFECTS OF SUBEQUILIBRIUM, SCALE ECONOMIES AND MARKUPS
}

\begin{abstract}
Measures of productivity growth typically include in the productivity "residual" the impacts of subequilibrium from fixity of factors, costs of adjustment, returns to scale and markups. This paper proposes a general two part framework for adjusting the residual measure to take these impacts into account. Errors computing the weights on output and quasi-fixed input growth in traditional measures are first corrected for both primal-and cost-side measures. Then the deviation of revenues from costs is used to decompose the full primal measure to identify the differential influences of technical change, utilization fluctuations, scale economies and price margins. Use of the framework is illustrated empirically for the U.S., Japanese and Canadian manufacturing sectors, using an econometric model that allows explicit incorporation and measurement of these influences. The adjusted measures show that a significant amount of cyclical and secular change in measured productivity growth can be attributed to production characteristics other than technical change, particularly scale economies.
\end{abstract}

\footnotetext{
Catherine J. Morrison Tufts University Department of Economics Medford, MA 02155
} 


\section{Introduction}

The literature on productivity growth measurement is primarily based on models which, implicitly or explicitly, incorporate restrictive assumptions such as instantaneous adjustment of inputs, constant returns to scale and perfect competition. Recently researchers have begun focusing on the importance of taking these characteristics of production processes into account to isolate the "true" productivity growth residual independent of these factors. The importance of returns to scale on productivity growth measurement, particularly on the cost side, was outlined by ohta [1975] and elaborated on by Morrison [1986] and Fuss and Waverman [1986] among others. Researchers such as Berndt and Fuss [1986], Hulten [1986] and Morrison [1986] have attempted to represent subequilibrium from quasi-fixity of inputs such as capital by relaxing the assumption that the market price captures the true marginal return, or shadow value, of the fixed input. In addition, a literature has begun to materialize, including Denny, Fuss and Waverman [1981], Hall [1988], Domowitz, Hubbard and Peterson [1988], and Morrison and Diewert [1988], which focuses on adjusting the Solow [1958] productivity residual for markup behavior.

Most of these models recognize only one deviation of the true economic return to an input or output from its market valuation. This is due to the nonparametric nature of the empirical implementation of these models, which precludes isolating the independent impacts. With a parametric econometric model, however, the deviations due to different factors can be independently measured and their impacts on the productivity residual individually assessed. To accomplish this requires constructing a measurement framework for adjustment of the productivity residual for these deviations and postulating a 
model for estimation. This paper offers such an integrated framework and model, and provides an empirical illustration that demonstrates the empirical significance of these adjustments.

Two components of the adjustment process are initially identified. The first is based on correcting the errors in measurement of productivity growth indexes due to differences between shadow values and observed input prices. This extends the approaches suggested by Berndt and Fuss [1986] and Hulten [1986] for subequilibrium. The second part recognizes the difference between cost and primal measures when the usual simplifying assumptions do not hold. It focuses on using the cost elasticity with respect to output and the output demand elasticity to decompose the primal residual measure into its components - true productivity growth (technical change) and the effects of other characteristics. This is analogous to the adjustments for subequilibrium and returns to scale suggested in Morrison [1986] from a dual cost perspective and for markups by Hall [1988] on the primal output side. Both these modifications may be thought of as reflecting error biases in the traditional measures.

A measurement procedure is then proposed to use for computation of these adjustments, based on the model in Morrison [1989a]. This model is built around a Generalized Leontief Restricted Cost Function developed in Morrison [1988], which allows for multiple quasi-fixed inputs and unrestricted returns to scale, and a similarly constructed demand function for output that incorporates imperfect competition in the output market. Using this model, measures are computed for the shadow values of fixed inputs, the extent of costs of adjustment, the degree of returns to scale, and the deviation between price and marginal cost for the U.S., Japanese and Canadian manufacturing sectors. Appropriate measures are then inserted into the framework for 
adjustment of productivity growth measures to yield productivity growth indexes for these industries that isolate technical change frow the effects of the other characteristics of the adjustment process.

The measured productivity growth indexes adapted to recognize subequilibrium and scale economies show that a substantial portion of cost declines generally attributed to technical change are instead explained by other production characteristics, particularly in years of large growth. These adjustments tend to smooth both cyclical and secular productivity fluctuations. Adaptations of output-side measures of productivity growth isolating the impact of price markups counteract evidence of productivity slowdowns over time. The modified indexes suggest that traditional measures increasingly underestimate productivity growth when markups are rising, as the markup estimates suggest is true. However, when the full series of corrections are made to accommodate low marginal (as compared to average) cost of production and capacity utilization fluctuations as well as markup behavior, the smoothing implication is at least partially offset. This results because the cost characteristics imply minimal profitability even with markup behavior, an empirical finding consistent with recent results of hall [1989].

\section{The Framework for Productivity Adjustment}

Analysis of productivity growth is based on determining the increase in efficiency of production over time. The concept of increasing efficiency can be formalized in either of two alternative forms; the potential growth in output when technology changes, holding the use of inputs fixed (the revenue or primal side), or the possible diminution of costs for given levels of output and prices of inputs (the cost or dual side). In the case of zero 
profits, choosing the first or second of these approaches is equivalent to focusing on either the left or right hand side of expression PYY-C, where $Y$ is output, $P_{Y}$ is the corresponding price, and $C$ is total costs. Computations based on the left hand side of this expression include returns to all cost and demand characteristics, whereas those based on the right hand side allow distinctions to be drawn among the impacts of different cost characteristics. These distinctions can be used to motivate development of a framework for decomposition of multifactor productivity growth measures to identify various determinants of increases in output production, or declines in cost of production, over time. In this section the standard approach to measurement of productivity growth is outlined and then adjustments are developed in turn to take scale economies, fixity, adjustment costs and markup behavior properly into account.

Ila. The Traditional Framework for Productivity Growth Measurement Assume firms face a production function $Y-Y(v, t)$, or equivalently a dual cost function which represents the technology, $C-C(P, t, Y)$, where $Y$ is output, $C$ is total costs, $v$ is a vector of $J$ inputs with corresponding prices $p$, and $t$ denotes technology (usually measured as a time counter). The various concepts underlying primal and dual productivity growth measures are represented using elasticities of these functions with respect to $t$ : specifically, $\partial \ln \mathrm{Y} / \partial t=\epsilon \mathrm{Y} t$ and $\partial \ln \mathrm{C} / \partial t=\epsilon_{\mathrm{C} t}$. These expressions reflect the residuals of total output (cost) growth less the contributions of the arguments of the functions other than $t$. Solow [1958] demonstrated that with perfect competition, constant returns to scale and instantaneous adjustment these residuals isolate technical change. 
The primal measure $\epsilon^{Y t}$ reveals the potential increase in output between two time periods using a given amount of inputs. Computation of this residual is accomplished using accounting or index number methods by calculating the output change normalized for the changes in inputs as $d \ln Y / d t-d \ln v / d t$ $=\dot{Y} / Y-\sum_{j} s_{j}\left(v_{j} / v_{j}\right)=\epsilon_{Y t}$, where $s_{j}$ is the share of input $j$ in terms of the value of total output $\left(\mathrm{P}_{\mathrm{j}} \mathrm{v}_{\mathrm{j}} / \mathrm{P}_{\mathrm{Y}} \mathrm{Y}\right)$. This equality is derived from the production function, where $d \ln Y / d t=(1 / Y) \bullet\left(\partial Y / \partial t-\sum_{j} \partial Y / \partial v_{j}\left(d v_{j} / d t\right)\right)$, recognizing that with profit maximization and perfect competition $p_{Y}\left(\partial Y / \partial v_{j}\right)-p_{j}$, and solving for the change in output independent of input changes, $\partial \ln Y / \partial t$. Similarly, the cost-side productivity growth residual or index can be measured as $(\mathrm{dln} c / d t-d \ln p / d t)=\left(c / c-\sum_{j} M_{j}\left(\dot{p}_{j} / p_{j}\right)=\partial \operatorname{lnc} / \partial t\right.$ - $\epsilon_{C t}$, where $c$ is unit costs $(c(p, t)=C(P, t, Y) / Y$ with constant returns to scale (CRTS)), and $M_{j}$ is the share of input $j$ in costs $\left(v_{j} p_{j} / C\right)$. This equality is based on manipulation of the unit cost function derivative dc/dt $-\partial c / \partial t+\sum_{j} \partial c / \partial p_{j}\left(d p_{j} / d t\right)$ analogously to the derivation of the primal measure using the production function.

Under the standard assumptions of CRTS, instantaneous adjustment and perfect competition, the dual cost share is equivalent to the primal output share $\left(S_{j}-M_{j}\right)$. In fact, with these restrictions on the production process, the primal and dual methods of measuring the productivity growth residual are identical - $\epsilon_{\mathrm{Yt}^{--\epsilon} \mathrm{Ct}}--$ as was shown by Ohta [1975].

Illustrating this relies on the equivalence of the cost and output shares, which results from the equality $\mathrm{P}_{Y} \mathrm{Y}=\mathrm{C}$; revenues just cover costs of production. More specifically, applying this equality to the cost residual

1) $\epsilon_{C t}=\frac{\dot{C}}{C}-\frac{\dot{Y}}{Y}-\sum_{j} \frac{P_{j} v_{j}}{C} \frac{\dot{P}_{j}}{P_{j}}$ 
and substituting $d \ln c / d t-\dot{C} / C-\sum_{j}\left(p_{j} v_{j} / C\right)\left[\dot{p}_{j} / p_{j}+\dot{v}_{j} / v_{j}\right]$ from the definition $C-\sum_{j} p_{j} v_{j}$, yields

2) $\epsilon_{C t}-\frac{\dot{Y}}{Y}+\sum_{j} \frac{P_{j} v_{j}}{c} \frac{\dot{v}_{j}}{v_{j}}-\frac{\dot{Y}}{Y}+\sum_{j} \frac{P_{j} v_{j}}{P_{Y}} \frac{\dot{v}_{j}}{v_{j}}--\epsilon_{Y t}$.

The equivalence of the two measures arises because constant returns implies no returns are generated from technological or supply characteristics such as scale economies; instantaneous adjustment guarantees no returns exist from varying utilization of inputs (the value of marginal products of inputs just covers their hire costs, so full utilization is maintained); and perfect competition ensures no returns to market power. However, if any of these assumptions is relaxed, returns or profits generated from the underlying supply and demand characteristics must be taken into account.

I Ib. Taking Account of Scale Economics

The importance of extending the traditional productivity growth framework for situations when returns to scale are evident was recognized by Ohta [1975]. In this case, the PYY-C equality does not hold because returns to the firm due to scale economies ${ }^{1}$ cause a deviation between marginal and average cost, and thus a difference between $\mathrm{P}_{Y}$ (which under perfect competition equals marginal cost) and average or unit $\cos t c-A C-C / Y$.

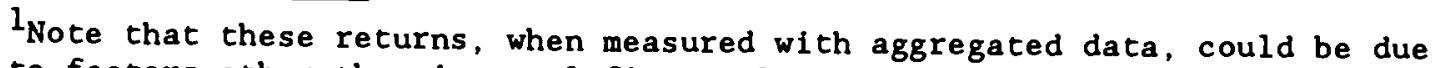
to factors other than internal firm scale economies. For example, "thick market" external benefits (mentioned in a number of recent macroeconomic studies including Hall (1989]) could also cause scale economies to be evident. Another possibility, proposed by Romer [1986], is that if knowledge has an increasing marginal product external economies will result which can be considered a scale effect even in the absence of technical change. The important consideration is whether scale appears to affect costs, independently of other factors.
} 
Intuitively, this means that the effects of exploiting returns to scale should be considered due to productivity growth but to a technological charactistic of the production process that allows firms to be more efficient at larger output levels independently of technical change. This suggests two adjustments to the measurement of multifactor productivity by cost-side measures.

The first simply requires recognizing that the usual cost-side measure is no longer valid when the assumption of constant returns to scale is invalid; it is incorrect and must be adjusted accordingly. In particular, the above measure based on unit cost changes presupposes that a unit cost function can be used, because the total cost function can be written as $C-Y c(p, t)$. If this is not the case, $\dot{c} / c-\dot{C} / C-\dot{Y} / Y$ becomes $\dot{C} / C-\epsilon_{C Y} \dot{Y} / Y$, where $\epsilon_{C Y}-\partial \ln c / \partial \ln Y$ weights the output change and is the inverse of returns to scale. This arises naturally from the Ohta derivation, where the standard measure is generated by recognizing that $\epsilon_{C Y^{-1}}$ with CRTS. More formally, the residual $\epsilon_{C t}$ must be adjusted to

3) $\epsilon_{C t}^{R}-\frac{\dot{C}}{C}-\epsilon_{C Y} \frac{\dot{Y}}{Y}-\sum_{j} \frac{P_{j} v_{j}}{C} \frac{\dot{P}_{j}}{P_{j}}-\epsilon_{C Y} \frac{\dot{Y}}{Y}+\sum_{j} \frac{P_{j} v_{j}}{C} \frac{v_{j}}{v_{j}}-\epsilon_{C t}+\left(1-\epsilon_{C Y}\right) \frac{\dot{Y}}{Y}$ where $R$ denotes the "Returns to Scale Adaptation", and the last term on the right hand side can be thought of as the bias correction when constant returns are inappropriately assumed. This bias may be implemented empirically using either a direct estimate of the elasticity of the cost function, or by taking the inverse of an independent measure of returns to scale, if one is available. 
The second adjustment, rather than correcting the traditional measure for an invalid assumption, adapts the cost side measure to be equivalent to the output measure. In particular, under CRTS the duality of the cost and production measures requires proportional cost and output changes, whereas when nonconstant returns exists this proportionality is lost. Thus, the cost change arising from a given output change must be divided into the contribution of the technological change itself and the return to scale economies. Ohta showed that this could be accomplished by multiplying ${ }^{\epsilon} \mathrm{Ct}^{\mathrm{R}}{ }^{\mathrm{Cy}}$ ${ }^{\epsilon} \mathrm{CY}{ }^{-1}$, or, ${ }^{-\epsilon} \mathrm{Ct}^{\mathrm{R}} /{ }^{\epsilon} \mathrm{CY} \mathrm{Y}^{-\epsilon} \mathrm{Yt}$. Conceptually this is a decomposition of the primal measure (which does not have a bias correction because the assumption $\epsilon_{\mathrm{CY}^{-1}}$ was not used for construction of the measure) into two parts, the effects of technical change and scale, since the output value reflects both characteristics of production. This adaptation can also be written in terms of an additive component; $\epsilon t^{--\epsilon} C t^{R}+\epsilon t^{R}[1-(1 / \epsilon C Y)]$, which again can be computed once an estimate of $\epsilon_{C Y}$ is obtained.

In a sense this adjustment simply adapts the cost shares to measure output shares, since $\epsilon_{C Y}-M C \cdot Y / C=P_{Y} Y / C$, where $M C$ is marginal cost and perfect competition is assumed. Thus, dividing by $\epsilon_{C Y}$ removes the weight from the output growth component of the measure and adapts the shares to be specified in terms of output values or true returns instead of costs.

One other point to mention is that, depending on the context and interpretation desired, either ${ }^{\epsilon} C_{t}{ }^{R}$ or ${ }^{\epsilon} \mathrm{Yt}$ might be more appropriate to use as a productivity growth measure. The important impact of ohta's discussion is to highlight the two independent factors incorporated in multifactor productivity measures, not to identify which measure is better, since in some circumstances one might think scale economies are a valid element of productivity growth that should be included in the measure. However, in most 
cases it would seem desirable to identify the individual contributions of technical change and scale. In such a case the decomposition of $\epsilon$ yt provides more interpretative potential. If only the technical impact is desired the ${ }^{\epsilon} \mathrm{Ct}^{\mathrm{R}}$ measure could be used alone or one could employ the primal measure ${ }^{\epsilon} \mathrm{Yt}$ multiplied by $\epsilon_{\mathrm{CY}}$ or divided by returns to scale. ${ }^{2}$

IIc. Recognizing Subequilibrium Impacts

In addition to scale economies, there are a number of other reasons the $\mathrm{P}_{Y} \mathrm{Y}-\mathrm{C}$ equality, and therefore the duality of the primal and dual productivity growth measures, may not hold. Some of these arise when the observed prices of inputs (or output) do not correctly reflect their marginal contribution to production. For example, if any inputs are fixed, the values of their marginal products may differ from their market prices so evaluation of their contribution by observed prices is generally invalid. In this case the shadow values of the fixed factors represent their true marginal economic contributions to the firm, and should be used for productivity growth computations. It may not be straightforward, however, to identify these shadow values.

One potential approach to measuring shadow values draws on another type of cost derivative or elasticity, that of a variable cost function with respect to a fixed input. More formally, a shadow value can be measured ${ }^{3}$ as $-\partial G / \partial x_{k}-Z_{k}$ for any fixed input $x_{k}$, where $G$ is the variable cost function $G(Y, P, x, t)$. In this functional representation, the fixity of $K$ factors in the vector $x$ is explicitly recognized, and the shadow values of these inputs, $z_{k}$,

\footnotetext{
${ }^{2}$ Note that dividing $\epsilon_{\mathrm{Ct}}$ by ${ }^{\epsilon} \mathrm{CY}$ is equivalent to multiplying $\mathrm{C}$ by ${ }^{\epsilon} \mathrm{CY}$, and vice versa for $\epsilon_{Y t}$ and $\mathrm{PY}_{\mathrm{Y}}$. This can create some confusion since at first glance this may appear to reverse the adjustments discussed above. 3 See Abel [1979] and Berndt, Fuss and Waverman [1980] for examples of the definition and use of this concept.
} 
$-10-$

represent the one period savings in terms of variable inputs possible on the margin if the fixed stock of $x_{k}$ were to be adjusted.

Using this notion, we can write total costs $C$ as $C-G+\sum_{k} P_{k} x_{k}$, where $P_{k}$ is the market price of input $x_{k}$, and shadow costs can be defined as $C *-G+\sum_{k} Z_{k} x_{K}$, which captures the actual or effective value of $x_{k}$ to the firm. $C$ and $C *$ will differ according to the true contribution to generating revenue, or marginal product, of the fixed inputs, so with perfect competition $c *$ by definition is equal to $\mathrm{PY}_{Y} \mathrm{Y}$. This equality, in fact, has often been used to compute an ex. post or residual measure of the returns to capital (K) as $P_{Y} Y-G-Z_{K} K$, assuming capital is the only quasi-fixed input and no other returns are mistakenly attributed to capital. ${ }^{4}$ Thus, this computation is based on the assumptions of CRTS, perfect competition and only one fixed input. We will return to elaborate on this further below.

The shadow cost function, defined by Berndt and Fuss [1986], has been shown by Morrison [1986] to be the basis of a cost-side capacity utilization measure $C * / C-C U_{C}$. When overall excess capacity exists the shadow valuation of the fixed inputs will fall short of their market prices on the margin, in which case this measure is less than one. If stocks are lower than economically optimal, however, the shadow values will exceed their market equivalents and the measure will exceed one ${ }^{5}$. Morrison [1986] also showed that $\mathrm{CU}_{\mathrm{C}}$ is equivalent to the short run elasticity of costs with respect to output, $\epsilon_{C Y}$, measured holding the quasi-fixed factors at their current levels and assuming long run CRTS. In sum, these relationships imply that with subequilibrium from fixity the $\mathrm{P}_{Y} \mathrm{Y}-\mathrm{C}$ equality becomes $\mathrm{P}_{Y} \mathrm{Y}-\mathrm{C} \cdot \mathrm{CU}_{\mathrm{c}}-\mathrm{C} \bullet \epsilon_{\mathrm{C}}-\mathrm{C} \star \neq \mathrm{C}$.

\footnotetext{
${ }_{5}^{4}$ See, for example, Berndt and Hesse [1985].

${ }^{5}$ Note that if some stocks exceed their economically optimal levels and others fall short of these levels the deviation of the capacity utilization measure from one is ambiguous; it will depend on the extent of the deviations for the different fixed inputs.
} 
Because the contributions to revenue can be separated in this fashion, it is possible separately to distinguish the impacts of utilization fluctuations and technical change on productivity growth using the capacity utilization measure $\mathrm{CU}_{\mathrm{c}}$.

Modifying the traditional productivity growth residuals correctly to reflect the impact of fixity can be thought of as simply evaluating fixed inputs at their shadow values. However, as in the case of returns to scale, the adaptation of the cost side measure can be expressed in terms of two conceptually different parts. First, both the standard primal-and cost-side measures must be adapted to correct for the invalid assumption of instantaneous adjustment, and then the relationship between the resulting ${ }^{\epsilon} C t$ and $\epsilon_{\mathrm{Yt}}$ measures can be used to decompose $\epsilon_{\mathrm{Yt}}$.

The first step toward correction of the cost measure is straightforward given the above development; the weight on the output growth term must again be $\epsilon \mathrm{CY}$. However, the deviation of this measure from one is now due to returns to the fixed input(s): $p_{k} f Z_{k}$. Therefore, to value these fixed inputs correctly this must be taken into account for measuring their shares. One way to think of this is to use the equality ${ }^{\epsilon} \mathrm{CY}-1-\sum_{\mathrm{k}}{ }^{\epsilon} \mathrm{Ck}$ where ${ }^{\epsilon} \mathrm{Ck}$ is $\partial \ln \mathrm{C} / \partial \ln \mathrm{x}_{\mathrm{k}}$ for the kth fixed input. This in turn is equivalent to $C \star / C$, since, based on the definitions of $C$ and $Z_{k}, \epsilon_{C k}$ can easily be shown to equal $\left(p_{k}-Z_{k}\right) x_{k} / C{ }^{6}$

Thus, if the Ohta derivation is reworked as in Morrison [1986], the two adjustments necessary to measure short run productivity growth correctly are

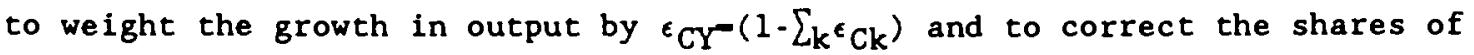
fixed inputs to be $z_{k} x_{k} / C$. On the primal side only this latter adjustment

\footnotetext{
${ }^{6}$ This arises from the assumption of CRTS and the definition of long run returns to scale as $\epsilon_{C Y}{ }^{L}=\partial \ln C / \partial \ln Y+\sum_{k} \partial \ln C / \partial \ln x_{k}=1$, which in turn is based on the long run constant returns assumptions $d \operatorname{lnx}_{k} / d \ln Y=1$ for all $k$. For further details, see Morrison [1986].
} 
must be done; the shares for fixed inputs should be weighted by $z_{k}$ rather than $p_{k}$. Thus the cost measure, $\epsilon_{C t}$, becomes

4) $\epsilon_{C t}^{F}-\epsilon_{C Y} \frac{\dot{Y}}{Y}+\sum_{j} \frac{P_{j} v_{j}}{C} \frac{\dot{v}_{j}}{v_{j}}-\sum_{k} \frac{z_{k} x_{k}}{C} \frac{\dot{x}_{k}}{x_{k}}=\epsilon_{C t}+\sum_{k} \epsilon_{C k} \frac{\dot{Y}}{\left(-\frac{x_{k}}{y}\right.}-\frac{\dot{x}_{k}}{x_{k}}$ where F stands for "Fixity recognized" and the last expression can again be thought of as a bias correction. ${ }^{7}$ In this case the bias occurs if instantaneous adjustment is assumed when subequilibrium really exists. This bias is computable either by constructing the elasticities, or by using a capacity utilization measure and the definition $1-\sum_{k} \mathrm{Ck}^{-\epsilon} \mathrm{CY}^{-C U}$, if a justifiable measure is available and one quasi-fixed input is assumed. Note that the bias depends on the relative growth rates of output and the fixed inputs since the standard assumption that $\epsilon_{C k}=0$ affects the weights on both these components of the measure.

Equation (4) is based on an output-side computation of the cost measure, where $d l n C / d t$ has been substituted, as in (2) as compared to (1) above. Alternatively, the cost side measure can be calculated directly, although the adjustment is not as straightforward. Instead of substituting $z_{k}$ for $p_{k}$ in this case, so that the measure would depend on the measures of $d \ln z_{k} / d t$, Morrison [1986] has shown that carrying out Ohta-type manipulations on the cost elasticity results in

5) $\epsilon_{C t}^{F}-\frac{\dot{C}}{C}-\epsilon_{C Y} \frac{\dot{Y}}{Y}-\sum_{j} \frac{p_{j} v_{j}}{C} \frac{\dot{p}_{j}}{p_{j}}-\sum_{k} \frac{P_{k} x_{k}}{C} \frac{\dot{p}_{k}}{p_{k}}-\sum_{k} \frac{\left(p_{k}-z_{k}\right) x_{k}}{C} \frac{\dot{x}_{k}}{x_{k}}$.

\footnotetext{
${ }^{7}$ It is worthwhile to note here that the sun of the shares does not equal one. This departure from one constitutes the adjustment between the cost and primal measures discussed below.
} 
$-\epsilon_{C t}+\sum_{k} \epsilon_{C k} \underset{y}{\left.\stackrel{\dot{y}}{-}-\frac{\dot{x}_{k}}{x_{k}}\right)}$

where the last equality is analogous to that in (4) and can be derived from the definitions $\epsilon_{C Y}-\sum_{k} 1-\epsilon_{C k}$ and $\left(p_{k}-z_{k}\right) x_{k} / C-\epsilon_{C k}$.

Although these two equivalent cost measures and the corresponding output measure $\epsilon_{\mathrm{Yt}} \mathbf{F}$ with the $\mathrm{x}_{\mathrm{k}}$ valued at their shadow values both correct traditional measures for the existence of quasi-fixed inputs, the cost-side index does not reflect the utilization changes captured in $\epsilon_{Y t}{ }^{F}$. The cost measure is based on an elasticity with respect to $C$ rather than $C \star$, and $C \neq C *-P Y Y$. Identifying the independent impacts of utilization and technical change on multifactor productivity growth, therefore, requires recognizing that the output side measure is a combination of these two types of returns. The decomposition of the multifactor productivity residual into its utilization and technical change components can be accomplished by showing again that $-\epsilon_{\mathrm{Ct}}{ }^{F} / \epsilon_{\mathrm{CY}}{ }^{-\epsilon} \mathrm{Yt}_{t}{ }^{F}$, or $-\epsilon_{\mathrm{Ct}}{ }^{\mathrm{F}} /\left(1-\sum_{\mathbf{k}^{\epsilon}}{ }_{\mathrm{Ck}}\right)-\epsilon_{\mathrm{Y}}{ }^{F}$ as in Morrison [1986]. This multiplicative decomposition can be transformed into an additive one similarly to that outlined for the returns to scale measure above.

An additional factor to include when utilization is an issue and a full dynamic adjustment process is specified is the portion of cost changes due to adjustment costs. In such a case, from Morrison [1986], (4) and (5) can be adapted to

$\left.4^{\prime}\right) \epsilon_{C t}^{A}=-\epsilon_{C Y} \frac{\dot{Y}}{Y}+\sum_{j} \frac{p_{j} v_{j}}{C} \frac{\dot{v}_{j}}{v_{j}}+\sum_{k} \frac{z_{k} x_{k}}{C} \frac{\dot{x}_{k}}{x_{k}}+\sum_{k} \frac{\dot{Z}_{k} \dot{x}_{k}}{C} \frac{x_{k}}{\dot{x}_{k}}$ 5') $\epsilon_{C t}^{A}=\frac{\dot{C}}{C}-\epsilon_{C Y} \frac{\dot{y}}{Y}-\sum_{j} \frac{p_{j} v_{j}}{C} \frac{\dot{p}_{j}}{p_{j}}-\sum_{k} \frac{p_{k} x_{k}}{c} \frac{\dot{p}_{k}}{p_{k}}-\sum_{k} \frac{\left(p_{k}-z_{k}\right) x_{k}}{C} \frac{\dot{x_{k}}}{x_{k}}-\sum_{k} \frac{\dot{z}_{k} x_{k}}{c} \frac{\dot{x_{k}}}{x_{k}}$ 
where A represents "Adjustment costs recognized". In terms of magnitude, however, the empirical work reported below indicates this adaptation is generally negligible and thus is of second-order empirical importance.

To this point scale economies and utilization have both been represented by $\epsilon_{C Y}$, where in the first case $\epsilon_{C Y}$ reflects a long run elasticity assuming instantaneous adjustment and in the second it is a short run elasticity assuming long run CRTS. However, using relationships already developed these two effects can individually be represented as components of the $\epsilon_{\mathrm{CY}}$ elasticity when both characteristics of the production process exist. In particular, it can be shown that the long run elasticity of costs with respect

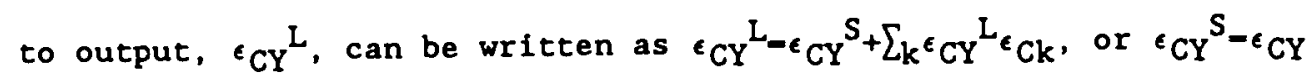
$-\epsilon_{C Y}{ }^{L}\left(1-\sum_{k}^{\epsilon} C k\right)$, where $L$ denotes long run and $S$ (or no supersript) short run. Since $\left(1-\sum_{k}^{\epsilon} C_{k}\right)-C_{c}-C \star / C$, as mentioned above, it is straightforward to show that $\epsilon_{C Y}-\partial \operatorname{lnC} / \partial \operatorname{lnY}=\epsilon_{C Y}{ }^{L} C U_{C}-(M C \bullet Y / C *) C U_{C}$. In other words, $\epsilon_{C Y}{ }^{L}$ is defined as $\partial \ln C / \partial \ln Y$ evaluated at the steady state value of the fixed inputs, $z_{k},{ }^{8}$ or $\partial C / \partial Y \bullet(Y / C *)-M C \bullet Y / C *$, where $M C$ is short run marginal cost. This scale measure captures the deviation between average cost (AC) and marginal cost because $A C \star \bullet Y-(C \star / Y) \bullet Y-C \star \not M C \bullet Y$.

Thus, with when both nonconstant returns to scale and subequilibrium exist, $\epsilon_{C Y}$ is a combined measure of both scale economies and capacity utilization. Adjusting the PYY-C equality for the difference between returns and costs requires multiplying $C$ by both components of ${ }^{C} \mathrm{CY}$ to obtain $P Y Y-C \cdot C U_{C}{ }^{\epsilon} C Y=Y^{L}-C \epsilon_{C} C Y^{L}-M C \cdot Y \not C * \neq C$. This collapses to the two earlier cases by setting $C *-C$ for instantaneous adjusment or $\epsilon_{C Y}{ }^{L}-1$ for CRTS. However, if

\footnotetext{
${ }^{8}$ Note we are simply evaluating the derivative at a given value of $z_{k}$, not allowing it to change, so short run marginal cost here does not include $\partial z_{k} / \partial x_{k}$.
} 
these assumptions are invalid and thus are not made, the adjustment by $\epsilon_{\mathrm{CY}}$, and the corresponding adaptation to the productivity growth measures, captures both the scale and fixed input effects. Again, if independent measures of scale economies and shadow values of fixed inputs (or capacity utilization with only one quasi-fixed input) are available, these measures may be used empirically to assess the difference between returns and costs. However, if both scale economies and capacity utilization, or multiple quasi-fixed inputs, exist, it is difficult consistently to identify these measures without employing a parametric framework.

Adjustments to correct productivity growth measures and decompose the primal productivity growth index when both nonconstant returns and fixity exist may also be carried out simultaneously by distinguishing the two parts of $\epsilon_{\mathrm{CY}}$. The correction to the cost measure requires multiplying the growth in output by $\epsilon_{\mathrm{CY}}-\epsilon \mathrm{CY}{ }^{\mathrm{L}} \mathrm{CU}_{\mathrm{c}}$ and valuing the shares of the $x_{k}$ at $z_{k}$ to generate

6) $\epsilon_{C t}^{T}--\epsilon_{C Y} \frac{\dot{Y}}{Y}+\sum_{j} \frac{P_{j} v_{j}}{C} \frac{\dot{v}_{j}}{v_{j}}+\sum_{k} \frac{Z_{k} x_{k}}{C} \frac{\dot{x}_{k}}{x_{k}}-\epsilon_{C t}-\sum_{k} \epsilon_{C k} \frac{\dot{x}_{k}}{x_{k}}-\left(\epsilon_{C Y}{ }^{-1}\right) \frac{\dot{Y}}{Y}$ where $T$ stands for "Total Correction" and the bias correction is analogous to the earlier cases. Similarly, modifying $\epsilon_{Y t}$ to $\epsilon_{Y t}{ }^{T}$ is accomplished as in the adaptation to fixed inputs by valuing the shares of fixed inputs at $z_{k}$. Also, costs of adjustment can be incorporated by adding terms analogous to those found in $\left(4^{\prime}\right)$ and $\left(5^{\prime}\right)$. Finally, the decomposition of productivity growth becomes $\epsilon_{C t}{ }^{T} /\left(\epsilon_{C Y}{ }^{L} C_{C}\right)-\epsilon_{Y t}{ }^{T}$, which independently identifies the three parts of $\epsilon_{\mathrm{Yt}}{ }^{\mathrm{T}}$. Again, which individual or combined measure is the most appropriate for measuring productivity growth depends on the context, but identifying the components individually refines the measure and facilitates understanding. 
IId. Allowing for Markups of Price over Marginal Cost

A final reason revenues ( $P_{Y} Y$ ) will not equal costs (C) is if market power exists so PyMC. This adjustment is somewhat different conceptually than the two already outlined; the market power adjustment can be thought of as a demand side adjustment, in contrast to the first two supply side adjustments that represent characteristics of costs facing the firm. In fact, the markup of price over marginal cost is $\mathrm{PY}_{\mathrm{Y}} / \mathrm{MC}-1 /\left(1+\epsilon_{\mathrm{PY}}\right)$ where $\epsilon_{\mathrm{PY}}$ measures the inverse demand elasticity facing the firm, implying that the markup is completely determined by the demand elasticity. This results because MC-MR in short run equilibrium for the profit maximizing firm, where MR is marginal revenue, so the expression for $\mathrm{P}_{Y} / \mathrm{MC}$ becomes $\mathrm{PY}_{\mathrm{Y}} /\left(\mathrm{PY}_{\mathrm{Y}}+\mathrm{Y} \bullet \partial \mathrm{P}_{\mathrm{Y}} / \partial \mathrm{Y}\right)$ $-\mathrm{p}_{\mathrm{Y}} /\left[\mathrm{P}_{\mathrm{Y}} \bullet\left(1+\partial \ln \mathrm{p}_{\mathrm{Y}} / \partial \ln \mathrm{Y}\right)\right]-1 /(1+\epsilon \mathrm{PY})$. The level of marginal cost simply determines which output level is chosen for evaluation of the markup.

To adjust for markups, the markup ratio $\mathrm{PY}_{\mathrm{Y}} \mathrm{MC}$ is used to adapt the $\mathrm{PY}_{\mathrm{Y}}-\mathrm{C}$

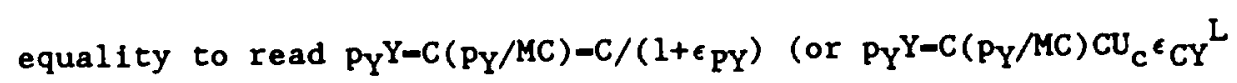

${ }^{-\epsilon} \mathrm{CY} C /(1+\epsilon \mathrm{PY})+\mathrm{MC} \cdot \mathrm{Y} \neq \mathrm{C} * \neq \mathrm{C}$ if nonconstant returns and subequilibrium also exist so $\epsilon\left(Y^{1}\right)$. This measure explicitly incorporates the dependence of revenue on the cost or supply and demand side elasticities; the adjustment factor ${ }^{\epsilon} \mathrm{CY} /(1+\epsilon \mathrm{pY})$ includes the elasticities of both cost and inverse demand with respect to output. Again the $\mathrm{PY}_{Y}$ measure captures returns to all characteristics of the production process that cause PYY $\neq C$, whereas $C$ includes only ex-ante returns to inputs.

Because the markup adjustment pertains to demand, the cost measure of productivity growth is not affected; construction of ${ }^{\epsilon} \mathrm{Ct}$ depends only on the cost elasticities and no PY-MC assumption is made. However, since markups affect the deviation between $P_{Y} Y$ and $C$, there will still be a difference between primal and dual productivity growth measures. This deviation reflects 
the impact of imperfect markets, and it can be isolated to determine the impact of technical change independently of market power. The implied decomposition is similar to those above; the adjustment factor can be used to show $\epsilon_{Y t}{ }^{T}=-\epsilon_{C t}{ }^{T}\left(1+\epsilon_{P Y}\right) / \epsilon_{C Y}$. Multiplication of the cost measure by $\left(1+\epsilon_{P Y}\right)$ accounts for the return to market power included in the denominator of the output shares, which should not be attributed to increased efficiency. The additive version of this decomposition is $\epsilon_{Y} t^{T}=-\epsilon_{C t}{ }^{T}+\epsilon_{C t}{ }^{T}\left[1-\left(\left(1+\epsilon_{P Y} \mid / \epsilon_{C Y}\right)\right]\right.$. Implementation of this decomposition may be carried out either by parametrically measuring the inverse demand and cost elasticities to construct the $\left(1+\epsilon_{P Y}\right) / \epsilon_{C Y}$ adjustment factor, or by using available estimates of the markup, capacity utilization and returns to scale.

It is worth remarking that the markup portion of this decomposition is analogous to the Hall [1988] notion of "correcting" the Solow [1958] primal productivity growth residual by evaluating the measure at marginal cost instead of price. Hall noted that the shares should be evaluated in terms of $M C \bullet Y$ instead of $P_{Y} Y$, implying that the $S_{j}$ should be multiplied by the markup ratio $\mathrm{P}_{Y} / \mathrm{MC}$. This is equivalent to multiplying $\epsilon_{Y}$ by the $1 /(1+\epsilon \mathrm{PY})$ measure elaborated above, which is the inverse of the decomposition process proposed here; it adapts the primal measure to reflect only the cost components. Which perspective or interpretation of this relationship is most relevant depends on the context. In addition, if subequilibrium, non-optimal capacity utilization or multiple quasi-fixed inputs also exist, Hall's nonparametric framework is not sufficient to untangle these effects.

III. A Related Concept -. Returns to Capital Measured as a Residual The analysis in the previous section of the deviation between PY $Y$ and $C$ when returns to scale, subequilibrium and market power are present 
$-18$.

distinguishes the returns to inputs from those to cost and demand characteristics. Thinking of this as a refinement of the concept of returns to inputs suggests another application of this decomposition, alluded to earlier. In particular, the above decomposition can be used to motivate the residual method of measuring capital returns and suggests an adjustment for this method if the cost and demand characteristics are important aspects of the production structure. It also allows further interpretation of the distinction between ex-ante and ex-post returns to factors and their role in this adjustment process. In this section I pursue these ideas further. More specifically, returns to capital are often measured as $P_{Y} Y-G$, or revenues less the payments to variable inputs such as labor and, perhaps, energy and materials if a gross output formulation is used. This is, of course, only valid if one quasi-fixed input exists so the residual method is justified. In this case, if instantaneous adjustment, constant returns to scale and perfect competition exist, this residual computation measures both an ex-post and an ex-ante return to capital.

However, in the absence of instantaneous adjustment, these returns reflect ex-post or shadow returns to capital, $Z_{K} K$, rather than the ex-ante or market returns $P_{K} K$. This can be seen by recognizing that $P_{Y} Y$ incorporates returns to fixity so $P_{Y} Y-G-C \bullet(C * / C)-G-C *-G-Z_{K} K$, or alternatively adjusting $P_{Y} Y$ by dividing by $C U_{C}-C * / C$ to capture only ex-ante returns; $P_{Y} Y \bullet(C / C *)-G-C-G-P_{K} K$. If instantaneous adjustment exists the measures will be equivalent. If subequilibrium prevails, however, they will not be. In the latter case either of these measures could be relevant depending on the application being considered. The important point is to recognize the difference when returns to fixity are incorporated, generating the ex-post measure, compared to when they are not, resulting in an ex-ante measure. 
Even this computation, however, does not correctly measure the returns to capital (either ex-ante or ex-post) if $\mathrm{PY}_{\mathrm{Y}}$ is capturing returns to scale and market power as well as those truly attributable to capital. In this more general case adjustments to $\mathrm{PY}_{\mathrm{Y}}$ analogous to those outlined for correcting primal-side productivity growth calculations must be carried out. If scale economies exist, $\epsilon_{C Y}{ }^{L}$ must be divided by $\mathrm{PY}_{\mathrm{Y}}$ to obtain an ex-post valuation purged of returns to scale; $P_{Y} Y(C * /(M C \cdot Y))-G-P_{Y} Y / \epsilon C Y=-G-Z_{K} K$, or both adjustments can be made to compute ex-ante returns as $P_{Y} Y(C / C *)\{C * /(M C \bullet Y)\}$ $G=P_{Y} Y(C /(M C \cdot Y))-G-P_{Y} Y / \epsilon C Y^{-G-P_{K} K}$. Similarly, the market power adjustment can be made to purge the $P_{Y} Y$ measure of the associated returns, resulting in $\mathrm{P}_{Y} \mathrm{Y}(\mathrm{MC} / \mathrm{P})(\mathrm{C} * /(\mathrm{MC} \bullet \mathrm{Y}))-\mathrm{G}-\mathrm{P}_{\mathrm{Y}} \mathrm{Y}\left(1+\epsilon_{\mathrm{PY}}\right) / \epsilon \mathrm{CY}^{\mathrm{L}}-\mathrm{G}-\mathrm{Z}_{\mathrm{K}} \mathrm{K}$, or both adjustments can be made to compute ex-ante returns as $\mathrm{PY} Y(M C / P)(C / C *)(C * /(M C \cdot Y))-G-P_{Y} Y\left(1+\epsilon_{P Y}\right) / \epsilon C Y^{-}$ $\mathrm{G}=\mathrm{P}_{\mathrm{K}} \mathrm{K}$.

These manipulations allow the residual method of measuring capital returns to be adjusted to reflect true returns to capital. This has a number of implications. First, if the distinction between $\mathrm{p}_{K}$ and $\mathrm{Z}_{\mathrm{K}}$ is not made, although the primal measure of productivity growth will be correct, it will not be possible to decompose it into the impacts of technical change and utilization.

In addition, if $P_{K}$ is measured as a residual, more adjustments must be made to carry out the modifications to productivity growth measures discussed in the previous sections. Productivity calculations from both the primal and dual perspective must be based on a corrected measure of returns to capital, $\mathrm{Z}_{\mathrm{K}}$, as discussed in terms of the adjustment to incorporate subequilibrium. Therefore, if $\mathrm{P}_{K}$ is computed as a residual in an attempt to measure ex-post returns to capital, but imperfect competition exists, the share of capital should be adapted to purge the returns to market power. This adds an extra 
dimension to the adjustment process for the productivity growth index; the price of capital measure must be corrected prior to the decomposition of this index.

Finally, a returns to capital or shadow value of capital equation is often estimated as part of a system of factor demand equations based on a variable cost function. The corrected residual computation suggests that this approach may be used even if returns to scale and imperfect competition exist. In particular, the shadow value equation procedure involves constructing a parametric expression for $Z_{K}-\partial G / \partial K$ for the estimation equation, and computing the dependent variable as $P_{Y} Y-G-Z_{K} K$. Once this is done, the adjustments suggested above can be made either to the left or right hand side of the equation to represent correctly the returns to capital independent of returns to these other characteristics, although in some cases this will result in a very complex equation for estimation purposes.

\section{Toward Empirical Measurement of the Adjustment Components}

The framework developed in the previous sections reveals that adfustment of the productivity growth residual or returns to capital relies on cost and (inverse) demand elasticities with respect to output that have standard interpretations; they are indexes of capacity utilization, returns to scale, and markup power. As mentioned earlier, if one can estimate these nonparametrically, as Hall [1988] does for the markup, or one has independent estimates of these values, such as published estimates of capacity utilization, these adjustments can be carried out directly. However, such measures may not be appropriate for the data set used, or may not correspond directly with the economic concepts they are designed to represent (and thus be mutually inconsistent). Therefore, it is convenient to use an econometric 
model that is capable of distinguishing these measures parametrically for a given body of data.

One model that can be utilized for this purpose is based on a Generalized Leontief restricted cost function and similarly constructed demand for output function, as developed in Morrison [1989a]. Combining the resulting representations of the technology, characterized by unrestricted returns to scale and multiple quasi-fixed inputs in the cost function, and of demand behavior, reflected in the inverse demand function, one can allow both factor demand and price decisions to be represented explicitly.

More specifically, the nonconstant returns to scale Generalized Leontief cost function with two fixed inputs, capital (K) and labor (L), and two variable inputs, materials (M) and energy (E), is

7) $G=Y\left[\sum_{i} \sum_{j} \alpha_{i j} P_{i}^{.5} p_{j}^{.5}+\sum_{i} \sum_{m} \delta_{i m} P_{i} s_{m}^{.5}+\sum_{i} p_{i} \sum_{m} \sum_{n} \gamma_{m n}^{s m} s_{n}^{.5}\right]$

$$
+Y^{.5}\left[\sum_{i} \sum_{k} \delta_{i k} p_{i} x_{k}^{.5}+\sum_{i} p_{i} \sum_{m} \sum_{k} \gamma_{m k} s_{m}^{.5} x_{k}^{.5}\right]+\sum_{i} p_{i} \sum_{k} \sum_{1} \gamma_{1 k} x_{k}^{.5} x_{i}^{.5}
$$

where $x_{1}, x_{k}$ denotes $K$ and $L, P_{1}$ and $p_{j}$ index the prices of $E$ and $M, s_{m}, s_{n}$ depict the remaining arguments $(Y, t, \Delta K$ and $\Delta L$ ), and including $\Delta K$ and $\Delta L$ allows for internal costs of adjustment on these inputs which reflects their quasi-fixity.

The inverse demand function for output is specified as

8) $\mathrm{D}^{-1}\left(\mathrm{EXP}, \mathrm{P}_{\mathrm{IM}}, \mathrm{r}, \mathrm{P}_{\mathrm{CPI}}, \mathrm{Y}\right)-\mathrm{P}_{\mathrm{Y}}-\left[\frac{\sum_{\mathrm{h}}^{\beta_{\mathrm{Yh}}{ }^{\rho_{h}^{.5}}}}{\mathrm{Y}}\right]^{2}$.

where $h$ indexes the components of the vector of shift variables for the demand function; in my empirical implementation h includes expenditure (Exp), the price of imports ( $P_{I M}$ ), the interest rate $(r)$, and the consumer price index $\left(\mathrm{PCPI}_{\mathrm{CP}}\right.$. 
These expressions are used to construct a system of estimating equations including ( 1 ) the cost function (7) plus the variable input demand equations for $E$ and $M$, derived from Shephard's Lemma; (ii) a MR-MC expression representing short run price setting using the expressions for marginal revenue $\left(M R-p_{Y}+\left(\partial p_{Y} / \partial Y\right) \bullet Y\right)$ and marginal cost $(M C-\partial G / \partial Y)$;

(iii) two Euler equations ${ }^{9}$ to reflect adjustment paths of the two inputs; and, to complete the system, (iv) the output demand equation.

This system of equations was estimated using three stage least squares, allowing for endogeneity of both output quantity and price as well as permitting nonstatic expectations on the input prices. The data set used includes similarly constructed data for U.S. manufacturing from Berndt and Wood [1984], Japanese manufacturing from Takamitsu Sawa at Kyoto University, and Canadian manufacturing from G. Campbell Watkins of DataMetrics in Alberta, Canada. For further elaboration on the data and estimation methods see Morrison [1989a,b]. The data were pooled for estimation, using procedures outlined in Morrison [1988]. Pooling the Canadian data with those for the U.S. and Japan alters the estimates for the U.S. and Japan (Morrison [1989a]) and for Canada alone (Morrison (1989b]) slightly but not substantively.

Based on the resulting parameter estimates, it is stralghtforward to compute the cost and demand elasticities required for the adjustment factor $\left(\epsilon_{\mathrm{CY}} \mathrm{L}_{\mathrm{CU}}\right) /\left(1+\epsilon_{\mathrm{PY}}\right)-\epsilon_{\mathrm{CY}} /\left(1+\epsilon_{\mathrm{PY}}\right) . \quad \epsilon_{\mathrm{PY}}$ is computed as $\partial \ln _{\mathrm{nY}} / \partial \ln \mathrm{n}$ using the equation for $p_{Y}$ in (8), and, using (7), $\epsilon_{C Y}$ is $\partial \ln C / \partial \ln Y-\partial \ln \left(G+P_{K} K+P_{L} L\right) / \partial \ln Y$. The individual components of $\epsilon_{C Y}$ can be further identified based on the definitions of returns to scale $\left(M C \bullet Y / C^{*}\right.$ ) and capacity utilization ( $\left.C * / C\right)$ from

${ }^{9}$ These are based on the Euler equation

$-G_{x}-r G_{\dot{x}}-P_{x}+G_{\dot{x} \dot{x}} \dot{x}+G_{x \dot{x}} \dot{x}=0$

developed in Berndt, Fuss and Waverman [1980]. 
the last section and noting that $M C-\partial C / \partial Y-\partial G / \partial Y, C *-G+Z_{K^{K}}+Z_{L^{L}}, Z_{K^{-}}-\partial G / \partial K, Z_{L^{--}}$ $\partial G / \partial L$, and $C-G+P_{K} K+P_{L} L$. Once these measures are calculated it is possible to determine the impacts of returns to scale, capacity utilization and the markup on productivity growth measures through computation of the the bias corrections and the decomposition of $\epsilon_{\mathrm{Yt}}$ as developed above.

v. Distinguishing the Components of Productivity Change: An Empirical Example

Let us designate $A D J=\varepsilon \mathrm{CY}^{\mathrm{L}} \mathrm{CU}_{\mathrm{c}} /\left(1+\epsilon_{\mathrm{PY}}\right)$ the full adjustment factor. The components of this measure, the combined numerator ${ }^{\epsilon} C Y{ }^{L_{C U}} U_{c}-\epsilon_{C Y}$ and $A D J$ itself are presented in the second to sixth columns of Table 1 for the U.S., Japan and Canada. ${ }^{10}$ ADJ tends to approximate one closely, which suggests zero profits on average for these countries due to the the relationship between revenues and costs. This interpretation stems from the equality $C \bullet A D J-P Y \bullet Y$, which implies $A D J$ measures $P Y / A C$ where $A C$ is short run average total cost with the fixed factors values at their ex-ante prices. Interestingly, although short run profits or losses are possible in this model, the components of ADJ tend to offset each other, which is consistent with the Hall [1989] suggestion that monopolistically competitive markets are predominant in the U.S.

For the U.S., in 1961-62 and 1974-80 average total costs at least slightly exceeded average revenue. However, in other years, especially 1968

\footnotetext{
${ }^{10}$ These estimates differ little from those in Morrison [1989a,b], but some deviation does arise due to pooling Canada with the U.S. and Japan. Although both capacity utilization and scale economies appear somewhat lower in the current estimates for the U.S. and Japan, the combined $\epsilon_{C Y}$ measure is virtually the same. This suggests a slightly different decomposition of cost changes in response to output variation -. a larger role for capacity utilization and smaller role for scale economies .- although the differences are not substantive. For Canada the cost elasticities are very similar although the measured markups tend to be slightly lower than when independent estimation is carried out.
} 
to 1971 , economic profits were earned; revenues were up to 98 higher than average costs. In Japan profits were even larger from 1960 to 1973, although in 1974 revenues fell short of costs and after that profits were not as large. 1980 and 1981 also appear to have been poor years for Japanese profitability. The worst years for Japan therefore follow immediately on energy price increases. In Canada profitability did not vary nearly as much, with revenues exceeding costs by two percent or more in most years, especially the late 1960 s to early 1970s. The only years average costs exceeded revenues for Canada were in the first part of the sample; energy price hikes did not appear to cause the problems with profitability experienced by the U.S. and Japan. However, this could at least partly result from including Canada's large petroleum refining industry in manufacturing, and from the fact that oil prices were constrained from rising to world prices in Canada.

The breakdown of the full adjustment index ADJ into its components provides additional information about what causes the deviation between costs and revenues. Economies of scale appear to be an important cost determinant for all three countries, especially in the later years. The figures in column two of Table 1 suggest that marginal cost increasingly falls short of average (total) cost over time. In this sense economies of scale exist and are becoming larger. This could be a result of increasing communications and computer technology, a broader world market, or a number of other changes in the cost structure of production, although identification of these determinants cannot be accomplished within this framework.

These cost patterns appear to be accommodated, in the U.S. and particularly Japan, by investment that results in excess capacity for firms, and by increasingly large price margins. Capacity utilization changes appear particularly important in Japan. It might be noted that the significant $\mathrm{CU}_{c}$ 
declines observed for Japan are a combination of large decreases in the shadow value to market price ratio for capital along with a smaller decline over time for labor. The weaker fall in $\mathrm{CU}_{c}$ for the U.S. arises because the $\mathrm{Z}_{\mathrm{L}} / \mathrm{P}_{\mathrm{L}}$ ratio in the U.S. increases slightly rather than decreasing over time. In Canada capacity appears instead to be overutilized. $C_{c}$ is larger than one even in the later years of the sample, although it falls toward one in 1975 and 1980 after the energy price increases. This is true even though the labor shadow value ratio drops somewhat over time.

The markup of price over marginal cost also has a noticable time trend, especially in Japan; as marginal costs decline relative to average costs, price margins increase to compensate. The markups are very similar in the U.S. and Canada, ranging usually between 108 and 208 , although in Japan they rise from 68 to 468 during this period. They also have a cyclical trend, although this pattern differs between Japan and the North American countries. In general, markups appear to decline during recessions; for example for all countries the 1973 and 1979 OPEC shocks are reflected in a downturn in the markup ratio. When all demand and supply impacts are taken into account, however, the correlations between $\mathrm{CU}_{c}$ and the markup suggest a tendency for procyclicality of markups in the U.S. and Canada but countercyclicality in Japan. This result for the U.S. and Canada is not particularly strong; for the three countries together there is a -.75 correlation between $\mathrm{CU}_{c}$ and the markup. 11

The impacts on productivity growth measures of the characteristics of production reflected in these indexes can be computed directly using the framework developed earlier. Adjustments to correct for the erroneous

${ }^{11}$ See Morrison [1989b] for further analysis of the cyclicality of markups and its determinants. 
assumptions of CRTS and instantaneous adjustment are reported in Table 2 for cost-side productivity growth, along with the implied bias corrections. The traditional cost-side productivity growth measure in the first column is computed by directly calculating equation (1) from the data using traditional index number procedures. The adjustment factors reported above are then used to modify the weights on the output and capital components to allow for scale economies, subequilibrium and adjustment costs, individually and then together, as outlined in section II.

The traditional measure in column one of Table 2 reflects the patterns generally associated with comparisons of secular and cyclical trends for these countries. Japan has the largest growth rate, although 1974 and 1975 were very poor years, with a 58 productivity decline in 1974 and a 18 drop in 1975. The U.S. experienced lower productivity growth and more years of productivity decline, with 1970 and $1974-75$ being the worst years. Canadian productivity growth appears roughly similar, with somewhat higher growth in the late 1960 s to early 1970 s and a worse productivity slump in the early 1980 s.

The second column captures the impact of correcting for scale effects by weighting output growth by $\epsilon_{C Y}$, as in (3). The impact of this adjustment is most apparent from the bias correction computations in the third column. Most of these numbers are negative, and the biases are particularly large in the mid-range of the sample and for Japan. The U.S. and Canada biases exhibit a very similar time trend. The negative values indicate that a substantial portion (up to more than 508) of cost decreases (productivity increases) observed have been erroneously attributed to technical change when instead they arose due to scale economies.

Adjustment for this causes the productivity declines in the 1974-75 period to be smaller than usually thought, especially in the U.S., because 
scale economies were not being exploited with stagnation in output growth during this period. In Canada, the slightly recessionary period of 1969-70 appears worse and only one year of productivity (technical change) Increase remains for 1978-82. In the U.S. scale economies were mainly apparent in the 1963-1969 period and were responsible for most of the cost declines generally attributed to technical change. The strong productivity growth observed for 1972-73 in standard measures is also tempered by this adjustment. In general, taking scale economies into account appears to smooth the productivity growth index; much fluctuation in productivity growth can be "explained" in terms of incorrect measurement of scale economies.

Adapting the productivity growth measure instead to permit subequilibrium, a procedure that yields the index in the fourth column, also results in many negative bias corrections. It is apparent that incorrectly dealing with slow adjustment of capital and labor stocks often causes overestimates of true productivity growth. The pattern is different than that for scale economies, however; in many cases the correction causes fluctuations to appear larger rather than smaller, especially for the U.S. and Canada.

The 1970 decline in the U.S., for example, is even greater than before and exceeds the drop in 1974, although the latter is also more substantial than originally estimated. This suggests from (5) that, given that excess capacity exists $\left(Z_{k}<p_{k}\right.$ overall), capital growth falls short of output growth. Later in the 1970s, however, some smoothing takes place; the decline appearing in 1975 is somewhat attenuated and the increases in 1976 and 1977 are smaller with the adjustment. Since $\mathrm{CU}_{c}$ is still below one in these years, this suggests relatively strong investment in this period. In Japan, by contrast, incorporating utilization changes actually cause measured productivity growth 
to improve for the earlier years, although not for 1976 to 1979 . Most of the negative biases for Canada also occur in the mid 1970 s and later, causing not only 1974-75 to look worse, as in the U.S., but also 1980-82. These bias numbers are not as large as for scale economies, however. Measures including adjustment costs explicitly, as in (5'), are reported in the next two columns. As seen there, incorporation of adjustment costs does not affect these patterns significantly.

The total effect of these adjustments, as reported in the last two columns, presents a very different picture of "true productivity", or technical change, than is generally perceived. In this scenario, 1966 to 1970 were really the years of the worst "productivity slowdown" in the U.S., in terms of technical change. Traditionally measured productivity increases resulted from incorrectly including the effects of scale economies and changes in utilization. Since 1971, however, true productivity appears to have improved; except for 1974 and 1978 productivity advances occurred every year, sometimes substantially. In Japan, by contrast, productivity growth in the early 1960 s was even better than standard measures indicate. However, much of the cost declines attributed to technical change in the late 1960 s and through the 1970s appear really to have been due to scale economies. For Canada the productivity growth indications are rather bleak for the post-1973 period; from 1974 on, only in 1976 was there positive true productivity growth. All other cost declines resulted from scale economies and utilization fluctuations. The only years in the sample which improve with the adjustments for Canada are 1960, 1975, and 1982, the latter two of which were originally the worst years.

These indexes suggest not only a smoothing process, or an "explanation" of standard productivity growth fluctuations, by correcting for restrictive 
assumptions, but also provide evidence of smaller productivity growth increases than generally thought for many years. Although the U.S. is performing better compared to earlier years and Japan is experiencing strong but not as spectacular productivity growth as often is thought, Canada is doing very poorly. Errors in computations are particularly serious when output growth rates are large or differ significantly from changes in quasifixed input stocks.

Some of the implications suggested by the indexes are highlighted by the average annual productivity growth rates provided for 1960-81 and pre- and post- 1973 at the bottom of Table 2, and by the standard deviations reported for the entire sample period.

For the U.S. the results are dramatic. The average growth rate as traditionally measured for the entire sample period is .8078 , which breaks down to .9768 and .5128 , respectively for $1960-73$ and 1973-84. Both the scale and utilization adjustments, however, absorb some of the observed cost increase, especially for the earlier period, leaving only a .3598 and .3588 annual average growth rate for the sub-periods. Further, the standard deviation of 1.030 from the corrected measure is considerably less than the $\sigma=1.254$ of the traditional procedure, indicating that for the U.S. correcting for biases reduces the cyclical variation.

For Japan, the 1.6598 and .4598 averages for the sub-periods both drop with adjustments, to 1.3158 and .4148 . Again the decline is greater for the first part of the sample -. the bias is. .344 as compared to -.045 - although the difference between the bias corrections for the two time periods is not quite as large as for the U.S. Also, the capacity utilization adjustment actually augments the traditional measure of technical change rather than 
$-30$.

removing a part of the observed growth. Recognition of subequilibrium, however, results in some smoothing in terms of the standard deviations; $\sigma=1.974$ for the traditional measures, but is 1.888 and 1.943 for the capacity utilization adjusted indexes with and without adjustment costs incorporated, respectively. This contrasts with the U.S., for which this adjustment somewhat increases the standard deviation.

For Canada, comparison with an analogous time period (only to 1981) suggests that the decreases from standard to corrected measures of technical change for both periods are almost of the same magnitude. The outcome of these adjustments is evidence of an increase in true productivity of .3718 per year through 1973, very close to that for the U.S., but a decrease of .4298 per year for the post-1973 period. This is a result of cost declines from both scale and utilization changes which have erroneously been attributed to technical change in traditional measures. The impact of scale economies was particularly strong during the earlier period due to greater growth. The standard deviation is also reduced by the adjustments, suggesting less fluctuations in measured productivity growth, although this smoothing results only from adjusting for scale economies; as for the U.S., adjustments for subequilibrium actually augment the variation.

Overall, in the adjusted measures, the much heralded productivity decline of the 1970s in the U.S. virtually disappears. For Japan and Canada the slowdown remains, but with lower overall levels of productivity growth attributed just to technical change for both periods. The evidence from the annual average growth rates thus reflects a smoothing of the often cited secular trends. The standard deviations also are reduced significantly with the adjustments, although most of this impact appears to stem from the 
smoothing effect of correcting for scale economies. This establishes some smoothing of cyclical patterns.

In addition to correcting the cost-side productivity growth measure for scale and utilization changes, the other element of the adjustment process discussed above is the decomposition of the full output-side productivity change measure from the corrected cost-side measure. To determine the impact of these adjustments we return to Table 1; the multiplicative factors that cause the deviation of the cost and primal side measures, are, of course, simply the indexes already presented there. Several comments are in order.

First note that the difference between the primal and dual productivity growth measures with all the adjustments taken into account is very small. This arises because the adaptation of the cost to primal measure simply requires dividing $-\epsilon_{C t}$ by $A D J$ (once all corrections to the weights in the measures are made), where $A D J$, as already discussed, closely approximates one.

Second, interpretation of the trends causing the deviations that do exist between the primal and dual measures is possible directly from the ADJ index; if the full productivity change $\epsilon_{\mathrm{Yt}}$ can be written as $-\epsilon_{\mathrm{Ct}} / \mathrm{ADJ}$, then the primal measure exceeds the cost measure as long as $A D J<1$. Some positive component of the output-side measure, therefore, can be attributed to scale economies, capacity utilization and markups during 1974-1980 for the U.S.; during the years 1974, 1980 and 1981 for Japan; and in 1960-61 for Canada. For the U.S. and Japan it tends to be the case that $\epsilon_{Y t}$ overstates the pure impact of technical change during recessionary years. Therefore these adjustments exaggerate both productivity declines and increases; if these are years of negative productivity growth, this means the primal measure implies the decline is worse than is really the case. 
If only one of these cost and demand characteristics is allowed for, however, interpretation of the decomposition of the output-side measure is ambiguous. For example, since $\epsilon_{C Y}{ }^{L}$ is less than one as long as economies of scale exist (true everywhere in this sample), ' ${ }_{Y} t$ always' appears to overestimate the impact of technical change if only this characteristic is taken into account in the decomposition of the primal measure. Since scale economies are increasing, this overestimation .. even for negative productivity growth years -- is greater in the later years of the sample.

Finally, if instead, the focus is to adjust for markups, the primal side productivity growth measure can be "corrected" by multiplying it by $\mathrm{PY} / \mathrm{MC}-1 /\left(1+\epsilon_{\mathrm{PY}}\right) .12$ This measure is presented in the last column of Table 1. Since the markup ratio always exceeds one and has been increasing, the adjusted measure always is greater than the standard measure, and any slowdown in productivity growth over time (as long as growth remains positive) appears less consequential with the adjustment.

Again, however, this independent adjustment for demand characteristics can be misleading if cost characteristics such as scale economies exist that should be accommodated; since these characteristics tend to counterract each other in terms of profitability. The advantage of the approach taken in this paper is that all these impacts are simultaneously considered within an integrated, coherent framework. Moreover, the empirical significance is substantial; for the U.S. when all the adjustments are taken into account the slowdown is entirely eliminated.

12 or, equivalently, by dividing by $(1+\epsilon \mathrm{PY})$. Note that this is equal to ${ }^{\epsilon} \mathrm{Ct} /{ }^{\epsilon} \mathrm{CY}$ from the definition of $\mathrm{ADJ}$. 


\section{Concluding Remarks}

This paper has provided an integrated framework for correcting and decomposing cost and primal productivity growth measures to consider the impacts of scale economies, subequilibrium, costs of adjustment and markup behavior. This framework has then been then used to assess productivity fluctuations in the manufacturing sectors of three countries, the U.S., Japan and Canada.

The results suggest that a significant portion of cost declines in production resulting from scale economies and capacity utilization fluctuations has been erroneously attributed to technical change. Since the marginal cost of production has fallen over time relative to average cost, this has contributed to observations of a productivity growth slowdown over time. Declines in capacity utilization, on the other hand, have sometimes obscured true productivity increases, particularly in Japan.

Two types of adjustments have been developed and implemented for identifying the impacts of these characteristics of production. The first corrects both cost and primal productivity growth measures for errors in the traditional measurement procedures typically used. These corrections involve changing the weight on the output growth term in the dual measure for both scale economies and fixity, and altering the weight on the quasi-fixed input growth terms in both primal and output measures to account for subequilibrium and adjustment costs. These adjustments, and the corresponding "biases" in the traditional measures, have been shown to have substantial empirical impacts on the trends reflected in productivity growth indexes.

The second adjustment can be thought of as a decomposition of the primal measure to identify the separate impacts of scale economies, fixity and markups on the full output-side measure of productivity growth. In total 
these adfustments have little impact on the trends reflected in the primal measure since zero profits appear to be the rule over time. This arises because scale economies are counterracted by markups of price over marginal cost. Therefore, adjusting by only one of these effects, such as markups, provides ambiguous information. For example, adjustment of the primal measure to value output at marginal cost, which can be thought of as decomposing ' $y t$ into its price and technical change components if $\epsilon \mathrm{CY}^{-1}$, implies $\epsilon_{\mathrm{Yt}}$ has increasingly understated productivity growth if markups have been rising, as appears to be the case. However, if it is recognized that ${ }^{\epsilon} \mathrm{CY}+1$ due to economies of scale and fixities, the remaining component of $\epsilon_{t}$ includes these effects. Incorporating this tends to neutralize the initial implication. The results reported here therefore provide a number of important insights about the relationships between different characteristics of production and economic performance indicators. They also suggest a partial "explanation" for observations of a productivity growth slowdown, since in periods of significant growth firms can take advantage of potential cost savings from scale economies and markups appear larger, resulting in an overestimate of productivity growth. This is evident, especially for the U.S. and Japan, for the late 1960s and early 1970s. The reverse occurs in the later 1970s. Capacity utilization fluctuations may, however, compensate at least somewhat for this; if expectations are optimistic, scale economies exist and current investment is therefore strong, capacity utilization may decline, which may cause measured productivity to be biased downward. This appears to be the case particularly for Japan in the 1970s and early 1980s. 
Table 1

Primal Productivity Growth and its Components, U.S., Japanese and Canadian Manufacturing

\begin{tabular}{|c|c|c|c|c|c|c|c|c|}
\hline Year & $-\epsilon^{-} \mathrm{Ct}$ & ${ }^{\epsilon} \mathrm{CY}^{\mathrm{L}}$ & $\mathrm{CU}_{\mathrm{c}}$ & ${ }^{\epsilon} \mathrm{CY}$ & $\begin{array}{l}\mathrm{PY} / \mathrm{MC} \\
/(1+\epsilon \mathrm{PY}))\end{array}$ & ADJ & $\begin{array}{l}\epsilon_{Y t} \\
\left.\epsilon_{C t} / A D J\right)\end{array}$ & $\epsilon_{Y} /\left(1+\epsilon_{\mathrm{PY}}\right)$ \\
\hline$\frac{U . S_{2}}{1960}$ & & & .996 & .916 & 1.105 & 1.012 & 1.725 & 1.907 \\
\hline $\begin{array}{l}1960 \\
1961\end{array}$ & $\begin{array}{r}1.745 \\
.334\end{array}$ & $\begin{array}{l}.919 \\
.921\end{array}$ & $\begin{array}{l}.990 \\
.984\end{array}$ & .906 & 1.100 & $\begin{array}{r}.997 \\
\end{array}$ & .335 & $\begin{array}{r}1.907 \\
.369\end{array}$ \\
\hline 1962 & 2.021 & .918 & .984 & .903 & 1.104 & .996 & 2.028 & 2.239 \\
\hline 1963 & -.630 & .905 & 1.005 & .910 & 1.118 & 1.017 & -.620 & -.693 \\
\hline 1964 & 1.978 & .900 & 1.006 & .906 & 1.124 & 1.018 & 1.942 & 2.183 \\
\hline 1965 & .105 & .890 & 1.013 & .902 & 1.139 & 1.026 & .102 & .116 \\
\hline 1966 & -1.453 & .882 & 1.014 & .894 & 1.152 & 1.030 & -1.411 & -1.627 \\
\hline 1967 & -.966 & .868 & 1.021 & .886 & 1.173 & 1.040 & -.929 & -1.090 \\
\hline 1968 & -.045 & .841 & 1.038 & .873 & 1. 219 & 1.064 & -.042 & -.051 \\
\hline 1969 & -.394 & .823 & 1.049 & .864 & 1.250 & 1.080 & -.365 & -.046 \\
\hline 1970 & -1.083 & .799 & 1.063 & .849 & 1.286 & 1.093 & -.992 & -1.276 \\
\hline 1971 & .614 & .810 & 1.055 & .854 & 1.261 & 1.077 & .571 & .719 \\
\hline 1972 & 1.120 & .832 & 1.033 & .859 & 1. 224 & 1.052 & 1.065 & 1.304 \\
\hline 1973 & 1.689 & .832 & 1.036 & .861 & 1. 222 & 1.052 & 1.605 & 1.961 \\
\hline 1974 & -1.152 & .872 & .987 & .860 & 1.150 & .989 & -1.164 & -1.339 \\
\hline 1975 & .571 & .884 & .961 & .850 & 1.128 & .958 & .595 & .672 \\
\hline 1976 & .487 & .888 & .953 & .846 & 1.126 & .953 & .511 & .575 \\
\hline 1977 & .343 & .886 & .941 & .834 & 1.128 & .940 & .365 & .411 \\
\hline 1978 & -.039 & .865 & .973 & .841 & 1.150 & .967 & -.041 & -.047 \\
\hline 1979 & .397 & .857 & .992 & .850 & 1.155 & .982 & .404 & .466 \\
\hline 1980 & 1.156 & .838 & 1.015 & .851 & 1.161 & .988 & 1.171 & 1.359 \\
\hline 1981 & 1.099 & .791 & 1.072 & .849 & 1.198 & 1.017 & 1.091 & 1.295 \\
\hline Japan & & & & & & & & \\
\hline 1960 & 6.051 & .977 & 1.137 & 1.112 & 1.060 & 1.178 & 5.135 & 5.444 \\
\hline 1961 & 1.705 & .975 & 1.078 & 1.051 & 1.065 & 1.120 & 1.523 & 1.622 \\
\hline 1962 & 2.022 & .965 & 1.080 & 1.042 & 1.086 & 1.132 & 1.787 & 1.940 \\
\hline 1963 & .731 & .959 & 1.073 & 1.029 & 1.102 & 1.134 & .645 & .711 \\
\hline 1964 & .228 & .952 & 1.068 & 1.016 & 1.124 & 1.142 & .200 & .224 \\
\hline 1965 & .110 & .945 & 1.058 & 1.000 & 1.140 & 1.140 & .097 & .110 \\
\hline 1966 & 1.231 & .942 & 1.057 & .996 & 1.154 & 1.150 & 1.071 & 1.236 \\
\hline 1967 & 2.699 & .937 & 1.043 & .977 & 1.171 & 1.144 & 2.359 & 2.763 \\
\hline 1968 & 2.167 & .926 & 1.036 & .959 & 1. 203 & 1.154 & 1.879 & 2.261 \\
\hline 1969 & 1.066 & .915 & 1.007 & .922 & 1.239 & 1.142 & .934 & 1.156 \\
\hline 1970 & 1.192 & .908 & .973 & .884 & 1.268 & 1.120 & 1.064 & 1.349 \\
\hline 1971 & -.923 & .893 & .950 & .848 & 1.317 & 1.117 & -.826 & -1.088 \\
\hline 1972 & .108 & .883 & .942 & .832 & 1. 353 & 1.126 & .096 & .130 \\
\hline 1973 & .024 & .878 & .937 & .822 & 1.384 & 1.138 & .021 & .029 \\
\hline 1974 & -2.588 & .881 & .855 & .753 & 1.324 & .997 & -2.596 & -3.437 \\
\hline 1975 & .188 & .863 & .869 & .750 & 1.360 & 1.020 & .185 & .251 \\
\hline 1976 & .412 & .858 & .882 & .756 & 1. 379 & 1.042 & .395 & .545 \\
\hline 1977 & .050 & .851 & .883 & .751 & 1.394 & 1.048 & .048 & .067 \\
\hline 1978 & .746 & .832 & .868 & .723 & 1.462 & 1.056 & .707 & 1.033 \\
\hline 1979 & 1.178 & .828 & .869 & .719 & 1.463 & 1.052 & 1.120 & 1.638 \\
\hline 1980 & 1.038 & .837 & .826 & .692 & 1.393 & .963 & 1.078 & 1.501 \\
\hline 1981 & 2.289 & .814 & .837 & .681 & 1.427 & .972 & 2.355 & 3.359 \\
\hline
\end{tabular}


Table 1, continued.

$\begin{array}{lrrrrrrrr}\text { Canada } & & & & & & & \\ 1960 & .738 & .943 & .983 & .927 & 1.066 & .988 & .747 & .796 \\ 1961 & .384 & .944 & .984 & .930 & 1.065 & .990 & .387 & .412 \\ 1962 & 2.013 & .932 & 1.030 & .960 & 1.075 & 1.032 & 1.950 & 2.096 \\ 1963 & -.393 & .933 & 1.020 & .951 & 1.075 & 1.022 & -.385 & -.414 \\ 1964 & .428 & .925 & 1.048 & .969 & 1.082 & 1.049 & .408 & .442 \\ 1965 & 1.531 & .916 & 1.029 & .942 & 1.091 & 1.028 & 1.489 & 1.625 \\ 1966 & -.474 & .898 & 1.053 & .946 & 1.111 & 1.051 & -.451 & -.501 \\ 1967 & -.429 & .895 & 1.047 & .936 & 1.116 & 1.045 & -.411 & -.459 \\ 1968 & .961 & .862 & 1.088 & .937 & 1.155 & 1.083 & .888 & 1.026 \\ 1969 & .030 & .835 & 1.103 & .921 & 1.194 & 1.099 & .027 & .032 \\ 1970 & -1.188 & .840 & 1.086 & .912 & 1.183 & 1.079 & -1.101 & -1.302 \\ 1971 & .681 & .854 & 1.063 & .907 & 1.161 & 1.054 & .646 & .751 \\ 1972 & .397 & .849 & 1.057 & .897 & 1.168 & 1.048 & .378 & .442 \\ 1973 & .515 & .849 & 1.066 & .906 & 1.166 & 1.056 & .487 & .568 \\ 1974 & -.739 & .865 & 1.050 & .909 & 1.142 & 1.038 & -.712 & -.814 \\ 1975 & -.955 & .870 & 1.031 & .897 & 1.131 & 1.014 & -.941 & -1.065 \\ 1976 & .225 & .844 & 1.058 & .893 & 1.157 & 1.033 & .218 & .252 \\ 1977 & -.199 & .779 & 1.096 & .853 & 1.221 & 1.042 & -.191 & -.233 \\ 1978 & -.373 & .845 & 1.048 & .886 & 1.149 & 1.018 & .366 & -.421 \\ 1979 & -.366 & .844 & 1.054 & .890 & 1.151 & 1.024 & -.357 & -.411 \\ 1980 & . .967 & .858 & 1.031 & .885 & 1.135 & 1.005 & -.962 & -1.093 \\ 1981 & -.058 & .823 & 1.071 & .881 & 1.164 & 1.026 & -.057 & -.066 \\ 1982 & -.346 & .810 & 1.079 & .873 & 1.166 & 1.018 & -.339 & -.396\end{array}$


Table 2

Cost Productivity Growth ( 8 ), Traditional and Corrected

\begin{tabular}{|c|c|c|c|c|c|c|c|c|c|}
\hline Year & $\frac{\text { Irad }}{{ }^{-} \mathrm{C} t}$ & $\frac{\text { Correct }}{{ }^{-} \mathrm{C}^{\mathrm{R}}}$ & $\frac{d}{\text { Bias }}$ & $-\epsilon C_{t}^{F}$ & Blas & $-\epsilon_{C t}{ }^{A}$ & Bias & $-\epsilon t^{T}$ & Bias \\
\hline$\frac{\text { U.S. }}{1960}$ & & & -.155 & 2.067 & -.004 & 1.900 & -.171 & 1.745 & -.326 \\
\hline $\begin{array}{l}1960 \\
1961\end{array}$ & $\begin{array}{r}2.071 \\
.331\end{array}$ & $\begin{array}{r}1.915 \\
.370\end{array}$ & $\begin{array}{r}-.155 \\
.039\end{array}$ & .300 & -.031 & .295 & -.035 & .334 & $\begin{array}{r}.520 \\
.003\end{array}$ \\
\hline 1962 & 2.679 & 2.021 & -.658 & 2.677 & -.002 & 2.669 & -.010 & 2.021 & -.658 \\
\hline 1963 & -.188 & -.611 & -.423 & -.233 & -.044 & -.210 & -.022 & -.630 & -.442 \\
\hline 1964 & 2.431 & 1.915 & -.516 & 2.472 & .041 & 2.496 & .066 & 1.978 & -.453 \\
\hline 1965 & .800 & -.001 & -.801 & .881 & .081 & .914 & .114 & .105 & -.696 \\
\hline 1966 & -.957 & -1.510 & -.554 & -.941 & .015 & -.893 & .064 & -1.453 & -.497 \\
\hline 1967 & -.184 & -.557 & -.373 & -.581 & -.397 & -.586 & -.402 & -.966 & -.782 \\
\hline 1968 & 1.051 & .339 & -.712 & .695 & -.356 & .689 & -.362 & -.045 & -1.096 \\
\hline 1969 & .430 & -.071 & -.502 & .208 & -.222 & .130 & -.301 & -.394 & -.824 \\
\hline 1970 & -1.198 & -.118 & 1.080 & -2.292 & -1.094 & -2.224 & -1.026 & -1.083 & .115 \\
\hline 1971 & 1.494 & 1.050 &. .445 & 1.142 &. .352 & 1.085 & -.409 & .614 & -.880 \\
\hline 1972 & 2.266 & .629 & -1.637 & 2.797 & .531 & 2.831 & .565 & 1.120 & -1.146 \\
\hline 1973 & 2.636 & 1.293 & -1.343 & 3.041 & .405 & 3.078 & .442 & 1.689 & -.947 \\
\hline 1974 & -1.124 & -.838 & .286 & -1.294 & -.170 & -1.443 & -.318 & -1.152 & -.028 \\
\hline 1975 & -1.107 & .070 & 1.177 & -.790 & .317 & -.577 & .530 & .571 & 1.678 \\
\hline 1976 & 1.838 & . 791 & -1.046 & 1.547 & -.291 & 1.488 & -.349 & .487 & -1.351 \\
\hline 1977 & 1.491 & .591 & -.900 & 1.200 & -.291 & 1.195 & -.296 & .343 & .1 .148 \\
\hline 1978 & .648 &. .012 & -.660 & .560 & -.088 & .593 &. .055 & -.039 & -.687 \\
\hline 1979 & .642 & .411 & -.231 & .666 & .024 & .624 & $\cdot .018$ & .397 & -.245 \\
\hline 1980 & .204 & .868 & .664 & .415 & .211 & .490 & .286 & 1.156 & .952 \\
\hline 1981 & 1.505 & 1.263 & -.242 & 1.627 & .122 & 1.353 & -.152 & 1.099 & -.406 \\
\hline Jape & & & & & & & & & \\
\hline 1960 & 4.414 & 3.931 & -.482 & 6.530 & 2.117 & 6.596 & 2.182 & 6.051 & 1.637 \\
\hline 1961 & 1.153 & .700 & -.453 & 2.403 & 1.250 & 2.206 & 1.053 & 1.705 & .552 \\
\hline 1962 & 1.843 & 1.463 & -.380 & 2.570 & .728 & 2.432 & .590 & 2.022 & .180 \\
\hline 1963 & .726 & .293 & -.433 & .971 & .245 & 1.197 & .471 & .731 & .006 \\
\hline 1964 & .302 & -.346 & -.648 & 1.032 & .730 & .921 & 619 & .228 & -.074 \\
\hline 1965 & .132 & -.211 & -.343 & .465 & .33 & .475 & .343 & .110 & -.022 \\
\hline 1966 & 1.525 & .830 & -.695 & 1.925 & .400 & 1.966 & .442 & 1.231 & -.294 \\
\hline 1967 & 3.164 & 2.118 & -1.046 & 3.809 & .64 & 3.797 & .633 & 2.699 & -.465 \\
\hline 1968 & 2.935 & 1.802 & -1.133 & 3.326 & .391 & 3.344 & .409 & 2.167 & -.768 \\
\hline 1969 & 2.294 & .975 & -1.319 & 2.404 & .110 & 2.412 & .118 & 1.066 & -1.228 \\
\hline 1970 & 2.658 & 1.311 & -1.347 & 2.579 & -.080 & 2.525 & -.13 & 1.192 & -1.466 \\
\hline 1971 & -.345 & -1.001 & -.656 & -.281 & .064 & -.293 & .052 & -.923 & -.578 \\
\hline 1972 & 1.161 & .134 & -1.027 & 1.055 & -.107 & 1.080 & -.081 & .108 & -1.053 \\
\hline 1973 & 1.269 & .206 & -1.063 & 1.047 & -.222 & 1.022 & -.246 & .024 & -1.245 \\
\hline 1974 & -5.438 & -4.336 & 1.102 & -4.037 & 1.401 & -3.576 & 1.862 & -2.588 & 2.850 \\
\hline 1975 & -1.253 & -.831 & .422 & -.029 & 1. 224 & -.176 & 1.078 & .188 & 1.441 \\
\hline 1976 & 1.627 & .651 & -.976 & 1.311 & -.316 & 1.266 & -.361 & .412 & -1.215 \\
\hline 1977 & 1.030 & .225 & -.804 & .761 & -.269 & .760 & -.270 & .050 & -.980 \\
\hline 1978 & 2.423 & 1.171 & -1.251 & 1.851 & -.572 & 1.842 & -.581 & .746 & -1.676 \\
\hline 1979 & 1.999 & 1.377 & -.622 & 1.753 & -.246 & 1.718 & -.281 & 1.178 & -.821 \\
\hline 1980 & .328 & .458 & .130 & .955 & .627 & .928 & .600 & 1.038 & .710 \\
\hline 1981 & 2.954 & 2.106 & -.848 & 2.984 & .030 & 2.995 & .040 & 2.289 & -.666 \\
\hline
\end{tabular}


Table 2, continued.

\begin{tabular}{|c|c|c|c|c|c|c|c|c|c|}
\hline$\frac{\text { Canada }}{1960}$ & .675 & .633 & -.042 & .785 & .110 & 781 & .106 & $\begin{array}{l}738 \\
384\end{array}$ & $\begin{array}{r}.063 \\
-\quad 250\end{array}$ \\
\hline 1961 & .634 & .410 & -.224 & .579 & -.055 & .604 & -.030 & & \\
\hline 1962 & 2.438 & 1.906 & -.532 & 2.525 & .087 & 2.550 & .112 & 2.013 & -.425 \\
\hline 1963 & .093 & $\cdot .354$ & -.448 & .117 & .023 & .066 & -.028 & -.393 & -.487 \\
\hline 1964 & .932 & .271 & -.661 & 1.076 & .145 & 1.111 & .180 & .428 & -.504 \\
\hline 1965 & 2.105 & 1.414 & -.691 & 2.238 & .133 & 2.249 & .144 & 1.531 & -.574 \\
\hline 1966 & .177 & -.551 & -.726 & .128 & -.049 & .284 & .108 & -.474 & -.650 \\
\hline 1967 & .268 & -.064 & -.331 & .100 & -.168 & -.082 & -.349 & $\cdot .429$ & -.697 \\
\hline 1968 & 1.690 & .934 & -.756 & 1.801 & .111 & 1.770 & .080 & .961 & -.729 \\
\hline 1969 & 1.009 & -.013 & -1.022 & 1.043 & .034 & 1.149 & .141 & .030 & -.979 \\
\hline 1970 & -.383 & -.255 & .128 & -1.331 & -.948 & -1.328 & -.945 & -1.188 & -.805 \\
\hline 1971 & 1.703 & .690 & -1.013 & 1.731 & .029 & 1.770 & .067 & .681 & -1.021 \\
\hline 1972 & 1.316 & .170 & -1.145 & 1.583 & .267 & 1.610 & .295 & .397 & -.919 \\
\hline 1973 & 1.688 & .337 & -1.350 & 1.915 & .228 & 1.948 & .260 & .515 & -1.173 \\
\hline 1974 & .161 & -.428 & -.588 & -.068 & -.228 & -.116 & -.277 & -.739 & -.900 \\
\hline 1975 & -1.013 & -.447 & .566 & -1.644 & -.631 & -1.544 & -.531 & -.955 & .058 \\
\hline 1976 & 1.041 & .267 & -.774 & 1.119 & .078 & 1.035 & -.006 & .225 & -.816 \\
\hline 1977 & .566 & .082 & -.485 & .362 & -.204 & .325 & -.242 & -199 & -.767 \\
\hline 1978 & .395 & -.589 & -.985 & .671 & .276 & .687 & .292 & -.373 & -.768 \\
\hline 1979 & .399 & -.590 & -.988 & .668 & .269 & .673 & .275 & -.366 & -.764 \\
\hline 1980 & -.972 & -.517 & .455 & -1.335 & -.363 & -1.441 & -.469 & -.967 & .006 \\
\hline 1981 & .249 & .235 & -.014 & -.074 & -.322 & -.044 & -.293 & -.058 & -.307 \\
\hline 1982 & -1.840 & -.028 & 1.812 & -2.837 & -.997 & -2.294 & -.454 & -.346 & 1.494 \\
\hline
\end{tabular}

Average Annual Growth Rates

\begin{tabular}{|c|c|c|c|c|c|c|c|c|}
\hline $\begin{array}{l}\frac{U}{1} S_{1} \\
1960-81 \\
1960-73 \\
1974-81\end{array}$ & $\begin{array}{l}.807 \\
.976 \\
.512\end{array}$ & $\begin{array}{l}.446 \\
.476 \\
.393\end{array}$ & $\begin{array}{r}-.361 \\
-.500 \\
-.119\end{array}$ & $\begin{array}{l}.735 \\
.874 \\
.492\end{array}$ & $\begin{array}{l}-.072 \\
-.102 \\
-.021\end{array}$ & $\begin{array}{l}-.084 \\
-.106 \\
-.046\end{array}$ & $\begin{array}{l}.359 \\
.359 \\
.358\end{array}$ & $\begin{array}{l}-.448 \\
-.619 \\
-.154\end{array}$ \\
\hline $\begin{array}{l}\text { Japan } \\
1960-81 \\
1960-73 \\
1974-81\end{array}$ & $\begin{array}{r}1.223 \\
1.659 \\
.459\end{array}$ & $\begin{array}{l}.592 \\
.872 \\
.102\end{array}$ & $\begin{array}{l}-.631 \\
-.787 \\
-.356\end{array}$ & $\begin{array}{r}1.608 \\
2.131 \\
.694\end{array}$ & $\begin{array}{l}.385 \\
.472 \\
.235\end{array}$ & $\begin{array}{l}.388 \\
.461 \\
.260\end{array}$ & $\begin{array}{r}.987 \\
1.315 \\
.414\end{array}$ & $\begin{array}{l}-.236 \\
-.344 \\
-.045\end{array}$ \\
\hline $\begin{array}{l}\text { Canada } \\
1960-82 \\
1960-73 \\
1974-81 \\
1974-82\end{array}$ & $\begin{array}{r}.580 \\
1.025 \\
.103 \\
-.113\end{array}$ & $\begin{array}{r}.153 \\
.395 \\
-.249 \\
-.224\end{array}$ & $\begin{array}{l}-.427 \\
-.629 \\
-.352 \\
-.111\end{array}$ & $\begin{array}{r}.485 \\
1.021 \\
-.038 \\
-.348\end{array}$ & $\begin{array}{l}-.095 \\
-.004 \\
-.140 \\
-.235\end{array}$ & $\begin{array}{r}-.069 \\
.010 \\
-.156 \\
-.189\end{array}$ & $\begin{array}{r}.062 \\
.371 \\
-.429 \\
-.419\end{array}$ & $\begin{array}{l}-.518 \\
-.654 \\
-.533 \\
-.307\end{array}$ \\
\hline
\end{tabular}

Standard Deviations

\begin{tabular}{|c|c|c|c|c|c|}
\hline$\frac{\text { U.S. }}{1960-81}$ & 1.254 & .917 & 1.409 & 1.389 & 1.030 \\
\hline$\frac{\text { Japan }}{1960-81}$ & 1.974 & 1.553 & 1.943 & 1.888 & 1.616 \\
\hline$\frac{\text { Canada }}{1960-82}$ & 1.026 & .647 & 1.318 & 1.269 & .793 \\
\hline
\end{tabular}




\section{References}

Abel, A.B. (1979), Investment and the Value of Capital, Garland Publishing Co. New York.

Berndt, Ernst R., Melvyn Fuss and Leonard Waverman [1980], Empirical Analysis of Dynamic Adjustment Models of the Demand for Energy in U.S. Manufacturing Industries 1947-74, Final Research Report, Palo Alto, California, Electric Power Research Institute, November.

Berndt, Ernst R., and Melvyn Fuss [1986], "Productivity Measurement Using Capital Asset Valuation to adjust for Variations in Utilization", Journal of Econometrics, Vol. 33, No. 1/2, Oct./Nov., pp. 7-30.

Berndt, Ernst R., and Dieter M. Hesse [1985], "Measuring and Assessing Capacity Utilization in the Manufacturing Sector of Nine OECD Countries," European Economic Review, Vol. 30, No. 5, October, pp. 961-989.

Berndt, Ernst R., and David 0. Wood [1984], "Energy Price Changes and the Induced Revaluation of Durable Capital in U.S. Manufacturing During the OPEC Decade", manuscript, M.I.T. Center for Energy Policy Research, January .

Denny, Michael, Melvyn Fuss and Leonard Waverman [1981], "The Measurement and Interpretation of Total Factor Productivity in Regulated Industries, with an Application to Canadian Telecommunications", in Productivity Measurement in Regulated Industrles, (Thomas G. Cowing and Rodney Stevenson, eds.), Academic Press.

Domowitz, Ian. R. Glenn Hubbard, and Bruce C. Petersen [1988], "Market Structure and Cyclical Fluctuations in U.S. Manufacturing". The Review of Economics and Statistics, Vol. 70, No. 1, February.

Fuss, Melvyn and Leonard Waverman [1986]. "The Extent and Sources of Cost and Efficiency Differences Between U.S. and Japanese Automobile Producers", N.B.E.R. Working Paper \#1849, March.

Ha11, Robert E. [1988], "The Relation Between Price and Marginal Cost in U.S. Industry", Jeurnal of Political Economy, Vol. 96, No. 5, October, Pp. $921-947$.

Ha11, Robert E. [1989], "Invariance Properties of Solow's Productivity Residual". Manuscript prepared for Robert Solow's 65 th birthday celebration, April.

Hulten, Charles (1985), "Short Run and Long Run Cost Functions and the Measurement of Efficlency Change", Journal of Econometrics. Vol. 33, No. $1 / 2$, Oct/Nov., pp. $31-50$.

Morrison, Catherine J. [1985], "Primal and Dual Capacity Utilization: An Application to Productivity Measurement in the U.S. Automobile Industry", Journal of Business and Economic Statistics, Vol. 3, No. 4, October, PP. 312-324. 
Morrison, Catherine J. [1986a], "Productivity Measurement with Nonstatic Expectations and Varying Capacity Utilization: An Integrated Approach", Journal of Econometries. Vol. 33, No. 1/2, Oct./Nov.. Pp. 51-74.

Morrison, Catherine J. [1988], "Quasi-Fixed Inputs in U.S. and Japanese Manufacturing: A Generalized Leontief Cost Function Approach", Review of Economics and Statistics, Vol. 70, No. 2, May. PP. 275-287.

Morrison, Catherine J. [1989a], "Markups in U.S. and Japanese Manufacturing: A Short Run Econometric Analysis, manuscript, February".

Morrison, Catherine J. [1989b], "Markup Behavior in Durable and Nondurable Manufacturing: An Applied Production Theory Approach", manuscript, March.

Morrison, Catherine J. and Ernst R. Berndt (1981), "Short Run Labor Productivity in a Dynamic Model", Journal of Econometries, Vol. 16, pp. $339-365$.

Morrison, Catherine J., and W. Erwin Diewert [1988], "New Techniques in the Measurement of Multifactor Productivity", manuscript, December.

Ohta, M. [1975], "A Note on the Duality Between Production and Cost Functions: Rate of Returns to Scale and Rate of Technical Progress", Economic Studies Quarterly, 25, pp. 63-65.

Romer, Paul M. [1986], "Increasing Returns and Long-Run Growth", Journal of Political Economy, 94, October, pp. 1002-1037.

Solow, Robert M. [1958], "Technical Change and the Aggregate Production Function", Review of Economics and Statistics, Vol. 39, No. 5, August, pp. $312-320$. 
</ref_section> 